\title{
Enhancing Classroom Communication With Interactive Technology: How Faculty Can Get Started
}

\author{
Jacqueline K. Eastman, (E-mail: jeastman@valdosta.edu), Valdosta State University
}

\begin{abstract}
This paper proposes that Interactive Technology can help professors enhance communication in the classroom so there is increased attention, interest, preparation, and retention of class materials by the students. Interactive Technology (also called audience response systems) involves students using individual response pads (clickers) to respond to questions asked in class by the professor. The students' responses are captured by a receiver and with the software available, professors can get instant feedback from their students to determine how well they understand the material presented. To get started using this technology, professors can either buy a system outright or utilize one in conjunction with their textbook. After attending a few training classes and working with their Information Technology people to install it in their classroom, a professor can start working with the system to enhance their interaction with students in class. This paper describes Interactive Technology in more detail and how to get started using it.
\end{abstract}

\section{INTRODUCTION}

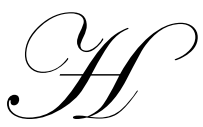

uman interaction is critical (Stiefelhagen, Chen, and Yang, 2005) and the quality of interaction and communication between professors and students has consistently been seen as an important component of learning (Karakaya, Ainscough, and Chopoorian, 2001). Two additional challenges faculty face are keeping the students' attention and obtaining useful feedback on the students' reaction to the class material (Terreri and Simons, 2005). One technological tool for professors to enhance communication in order to improve attention, feedback, and interaction with students when they are presenting material is Interactive Technology (also called audience-response systems) (Terreri and Simons, 2005).

The Interactive Technology described in this paper involves the use of individual response pads that students would utilize in class to answer questions posted via PowerPoint. There is a wireless response system (hooked up to a professor's laptop computer or to a desktop computer in the classroom) that gives the professor immediate feedback from every student in the class. Each student would have an individual response pad that looks similar to a TV remote control device; the individual response pads would be numbered with each student having one response pad that they would use for the entire semester. The software creates an electronic code that it assigns to both a keypad and a keypad user's profile; this information is merged and can be exported to a database or spreadsheet (Krantz, 2004). The professor could post a question via a PowerPoint slide and the students would individually click their response. On the PowerPoint screen it would note each number pad and if they responded (it would not show their individual response onscreen, just that they responded). There would be software then on the computer that could be used to instantly track responses by an individual student and post the aggregate results. With this technology, professors get instant, specific feedback and students get the chance to express themselves and see what others in the class are thinking (Terreri and Simons, 2005). Thus, Interactive Technology may aid faculty in enhancing classroom communication and interaction.

The purpose of this paper is to discuss the use of Interactive Technology (such as the Classroom Performance System by eInstruction) and address how faculty can utilize this to enhance classroom communication in order to increase students' attention, interest, preparation, and retention of class materials. Oftentimes in a class discussion it 
is the same students that participate; even when that participation is graded. Also, students are often under prepared for class and the material being discussed (Massey, Brown, and Johnston, 2005). Furthermore, students are disappointed in a class if it is not entertaining enough for them (Roberts, 1999). Finally, both students and faculty are concerned when as a result of these issues, students perform poorly. Thus, in this paper, the author first presents a literature review describing the benefits and uses of Interactive Technology, how to get started using Interactive Technology, and the best practices with Interactive Technology. Then, the author presents her experience with Interactive Technology, the assessment of Interactive Technology, and the conclusions.

\section{LITERATURE REVIEW}

Interactive Technology (audience response systems) using individual key response pads (clickers) to get input from an audience has been used in a variety of ways from a TV show audience ("Who Wants to be a Millionaire?"), to meeting/seminar/conference attendees (Hatch, 2003; Krantz, 2004) to students in a classroom (Kurdziel, 2005; Unmuth, 2004). At universities it has been utilized in a variety of fields including philosophy, mathematics, engineering, architecture, physics, computer science, psychology, and medicine (Carnaghan and Webb, 2005 , p. 4). The medical field has used it extensively for training, presentations, and conferences (Merritt, 2000; Pelletier, 2004; Radnor, 2005).

\section{BENEFITS AND USES OF INTERACTIVE TECHNOLOGY}

Kurdziel (2005) notes five reasons for educators to use an audience response system: (1) limitations of traditional lectures, (2) engaging students, (3) feedback to students and instructors, (4) learning gains, and (5) attitude gains. The key benefit is that it allows one to get instant feedback (Merritt, 2000). For the professors they can get immediate feedback to see how the class as a whole is performing, while tracking individual students behind the scenes to pinpoint specific concerns (Terreri and Simons, 2005, p. 36). Additional benefits are that students know that their opinions are being heard equally and professors have real-time information as they get an instant snapshot of what the audience is thinking (Terreri and Simons, 2005). Finally, Carnaghan and Webb (2005) note the benefit of increasing interactivity regardless of class size and that professors can focus on problems revealed by the students' responses.

Per eInstruction Corporation who markets the Interactive Technology product called the Classroom Performance System, the benefits and uses include: (1) assessing what students already know so class time can be used more effectively; (2) measuring comprehension of homework to know what topics are still not understood; (3) reviewing exam topics; (4) applying concepts just learned to determine if students understood what was just presented; (5) recording attendance; (6) questioning students at the start of class on materials covered in the past class or assigned for homework; (7) taking anonymous surveys to determine students' opinions on the course; and (8) giving quizzes or tests (eInstruction, 2005).

A professor could post an opinion question and have students click their response that would immediately be tallied and shown on the PowerPoint presentation so the class could see what percentage of students responded to each choice. Professors could do questions at the start of class to determine if the students read the assigned material (Kurdziel, 2005). It could also be used during class to determine if students understood a concept (Kurdziel, 2005). Other uses include getting a quick survey on course issues, quizzes/testing and for taking attendance (Kurdziel, 2005). Hatch (2003) suggests the following uses for audience response technology: two-tier questions (initial questions with follow up items), brainstorming (measuring reaction to ideas), pre and post testing of material learned, as an icebreaker to start a lesson, and feedback (especially when anonymous feedback is useful). Each student would have an assigned individual response pad so that professors could track who was responding, who was attending, and what their scores were; but their responses would be anonymous to the other students. Thus, there are a number of ways that professors could benefit from using Interactive Technology to enhance communication.

Finally, one of the advantages of using Interactive Technology is that most professors are familiar with PowerPoint and have materials in this format (Stone, Escoe, and Schenk, 1999). A professor can take their existing PowerPoint presentations and utilize them with Interactive Technology; such as, one's lecture slides can be linked into 
the lessons function of eInstruction and new and/or existing questions can be included through using the verbal function that will track responses. Several of the issues that professors faced when they first developed their PowerPoint lecture slides still remain, however, such as not putting too many items on one slide, avoiding small fonts, recognizing that some colors do not project as well (such as light colors or red), and that slides that replace note taking may reduce student attention (i.e. slide handouts should aid students in organizing material but not replace all note taking) (Stone et al., 1999).

\section{HOW TO GET STARTED USING INTERACTIVE TECHNOLOGY}

There are several audience response systems used at the college level including EduCue's PRS, HITT, and eInstruction (Kurdziel, 2005). For example, eInstruction, is already being used at more then 500 universities (Terreri and Simons, 2005). There are a variety of ways of obtaining these systems. One is to buy a system outright that includes all the hardware (such as student response pads and receiver) and software/support components. For an individual classroom, these systems typically cost under $\$ 2000$ from firms such as eInstruction and Turning Technologies (Turning Point) and include 32 response pads (Bradley, 2005; eInstruction, 2004). For more than an individual classroom, for example Wichita State's Business School has wired all of its classrooms with the Classroom Performance System, it cost approximately $\$ 6000$ (Unmuth, 2004).

Another method is to adopt a textbook from a publisher utilizing Interactive Technology. If enough new textbooks over a long enough time frame (such as year) are projected, the publisher may provide the hardware (receiver) and software for free. Typically with these systems, students will still need to buy response pads, which can range in cost from $\$ 12$ (eInstruction, 2004) to $\$ 25$ (Bradley, 2005) not including the bookstore markup. Additionally, if the software that goes with the system used by the publisher is proprietary (for example the software used with eInstruction is proprietary while the software used with Turning Point is not), students may also need to buy an access code which can cost $\$ 15$ or less (eInstruction, 2004). The textbook can be bundled with the response pad and access code or these items can all be purchased separately.

\section{BEST PRACTICES WITH INTERACTIVE TECHNOLOGY}

Kurdziel (2005) offers the following best practices with Interactive Technology: the focus should be on using the technology to enhance learning, the portion of the total grade for clicker items should be low (under 10\%), the system should be used regularly (two to four questions per class), and exams should measure conceptual understanding and critical thinking. Carnaghan and Webb (2005) suggest using four to six questions with this technology per eighty minute class. Finally, in terms of writing questions, suggestions include having questions of intermediate difficulty (if the question is too easy students will not feel like they need to listen to the lesson) (Kurdziel, 2005; Pelletier, 2004), and the questions should have various options (i.e. not yes/no) and include opinion questions, as just factual questions will bore the students (Pelletier, 2004). Something else to consider when creating questions is that if the vast majority of students get them correct, those that did not might be afraid to ask questions about the topic feeling that the majority of their classmates understood the topic (Carnaghan and Webb, 2005).

\section{ONE PROFESSOR'S EXPERIENCE WITH INTERACTIVE TECHNOLOGY}

The author decided to utilize Interactive Technology recently when her student evaluation scores in one major level business course continued to decline and the students' comments suggested that they thought the class was boring and the textbook useless. The author had tried a variety of participation activities before with mixed results, even when participation was graded. So the author decided she needed to do something different.

The author decided she needed a new textbook and looked for a publisher in which she both liked the textbook and that would support Interactive Technology. There was a bit of a learning curve for both the salesperson and the author in figuring out what was available. In agreement for using the book for a year, bundled with the eInstruction student access, the publisher provided the author's school with a receiver and software. The author received the infrared receiver a few months before she was to use the technology, but now there is also a radio frequency style receiver available. In terms of software and how the receivers work, there seems to be little 
difference. If one had a very large class and/or had a class where the students would need to do calculations for their participation, the radio frequency receiver would be the better choice as their keypads are alpha-numeric.

The author was concerned with how hard it would be to learn a new technology. Fortunately, the publisher offered a variety of online/conference call seminars using WebEx to teach faculty. The author attended two online seminars dealing with eInstruction's Classroom Performance System (their Interactive Technology product). The first was "CPSOnline Class Setup and Navigating the Software," and the second was "Creating CPS Content, Understanding the Gradebook, and Using Reports." Each seminar was about 90 minutes and had about one to two dozen faculty participate from all over the country teaching different subjects. The online classes were well run, there was a lot of opportunity to ask questions, and the follow-up materials provided were helpful. To practice with the technology, the author set up a demo class and practiced with that. The author had no problems loading the software. When the author had questions, there was a help desk available. To set up the actual class on the classroom desk top, the author utilized her school's Information Technology support staff and with the eIntrstruction's help desk, they were able to load the software, create icons so the author could transfer materials from the desktop to her laptop, and set up the class.

If a student can work a TV remote, they can work the keypad. A concern was making sure the students got their materials quickly, got logged into the system, and understood how to go online to check their participation grade. The training seminars provided a PowerPoint handout to show the students how to get the access code and get into the system. The author expanded on this to include sample questions, explained how the students could find their participation grades after each class, and reinforced the policy the author had created for using the technology and how it impacted a student's grade. The first semester, the author utilized one class day to do this and had the Information Technology people bring in laptops and they did it all together. Other professors the author spoke with did not do this and instead provided the materials to the student for how to do it outside of class. The author did it this way the second semester and the students were easily able to get into system.

The author recommends that professors give the students a week to get into the system and utilize that week as a practice week for the students and the professor. Also, the professor needs to remind students that to get into the system, the students need the class key code (given to the professor when they set up the class by eInstruction), the access code (purchased either directly from eInstruction online or bundled with the textbook), and the serial number on the back of their keypad; when the author had students say they could not get into the system, it was typically due to forgetting one of these items. Finally, it was important that the author's expectations for students using Interactive Technology was clearly spelled out in the syllabus. Thus, the author created a detailed Interactive Technology Policy section in the syllabus shown in Exhibit One.

\section{Exhibit One: Interactive Technology Policy In Syllabus}

- If the student does not have the textbook and access code, he/she can't get into the system. The student will not get credit for participation till he/she is in the system. If the student misses class, shows up late, or leaves early, he/she is not in the system for those questions missed and will not get credit for those questions for participation. The professor takes attendance at the start and end of class. If the student loses his/her keypad (clicker), he/she will not get credit for participation for the classes he/she did not have the clicker for and will have to buy a new keypad.

- While some of the questions are opinion questions with no one right answer, other questions deal specifically with the content and there is only one right answer. To get the credit for these questions, the student must get these questions right. In order to do this, the student will need to read the assigned chapter and PowerPoint notes before class and pay attention in class.

- $\quad$ There is a limited time to answer the CPS questions. Each student needs to be prepared to click his/her response quickly. All work for the course is to be done an individual basis. 
- $\quad$ Some of the CPS questions require further class participation then just clicking an answer. These will be noted by asking the student to click $\mathrm{A}$ if he/she wishes to participate and $\mathrm{B}$ if he/she does not want to participate. If the student clicks A and then is unprepared to participate when called on, he/she will not get credit for that question.

- If the student is not in class, he/she will not get credit for participation for the questions he/she missed. Having a classmate use another student's clicker to respond for them for any reason is considered cheating by both parties (both the person who was absent and the person who clicked for them). Cheating of any kind will not be tolerated and will result in a $\mathrm{F}$ for the course. If the student is having problems with his/her clicker, please report it to the professor immediately.

- If the student is representing the University in an approved function outside of class during class time, his/her absence will be excused, but to get credit for participation he/she must submit a typed response to each of the questions for that chapter listed in the PowerPoint slides ahead of time. These responses must be submitted at least 24 hours in advance of class and it is the student's responsibility to ensure that the responses were received in sufficient time. For those questions that require additional participation, the student will need to provide some details in order to get credit for those questions.

- $\quad$ The student can check his/her daily participation grade online and the professor recommends the students do this on a weekly basis. It is the student's responsibility to check this and to make sure he/she is getting the proper credit for his/her responses. If the student feels that he/she is not getting the proper credit, he/she needs to document this concern in writing within one week of the day he/she feels he/she did not get proper credit.

The author decided to utilize the technology in the following ways. First, the author created opinion questions (in which any answer was correct) to introduce the topics. Having students see the histogram of how everyone responded in their class to the question was extremely helpful in discussing a topic. For example, to illustrate the power of word-of-mouth in trying a new product, the author asked students what made them try a new food product; when they saw that the majority of them did so because they heard about it from family and friends rather then through sampling, coupons, or advertising, the concept was more vivid to them.

Second, the author created open-ended questions (click A, the correct answer, if the student wanted to participate and B if the student did not). Those students who click A would then be selected at random to participate (the technology has a means to randomly select students). It needs to be noted though, that random function will select any student from random (not just those who clicked A). The students figured that out quickly when students who were absent were being selected at random; however, knowing that their name could flash on the screen and everyone in the class would know they were absent may have helped improve attendance.

Finally, the author created multiple choice questions to measure the students' knowledge of the material. The author created one question for each objective in the chapter and after discussing the objective, posted that question. Only those students who got the question right, got the credit for it. If too few students answered correctly, the author knew she had to go back and reinforce the material before moving on to the next objective. The author made the questions difficult enough that the students would have to both read the material and pay attention in class to answer it easily. These questions were then included on the exams so there was an incentive for the students to make sure they learned it. For those objective questions that less then half the class got correct, the author had follow up questions ready to reassess learning after additional explanation (these extra questions were not included on the exam). The author found that when students visually saw that they got the question wrong, they were much more vocal in trying to understand why it was wrong then when they just discussed sample questions verbally. In the author's opinion, she would much rather have these discussions before an exam, rather than students fighting for points after an exam. 
For each chapter, the author had approximately six to eight questions and the questions were interspersed thoughout the material. Participation was graded daily based on the number of questions right divided by the number of questions asked that day. The average for participation was worth five percent of the student's final grade for the course. To create the PowerPoints, the author utilized the ones provided by the publisher and revised them to include other topics the author wanted to cover along with the discussion questions for each chapter. The author then linked these into the lessons function of eInstruction and used/tracked the questions with the verbal function. It took the author about a month or so to learn the technology and revise the PowerPoints for the class.

\section{ASSESSMENT}

Liu and Beamer (1997, p. 64) note that evaluation criteria of a teaching tool include "effectiveness of presentation of the message, usefulness for application by the user, and retention by the user." The literature suggests that Interactive technology can be very useful in gaining the attention and interest of students as they will have the opportunity to share their ideas in an anonymous way and knowing that they will have to respond frequently, will pay more attention to the material presented (Terreri and Simons 2005; Unmuth 2004). Stone et al. (1999) suggest that seeing their responses on screen in a class increases their importance and thus their involvement. Kurdziel (2005) reported that attendance is up to the $80 \%-95 \%$ range with classes using this technology.

There has been little empirical research on the impact of Interactive Technology on learning. In one study (using different sections of a management course with a control group, and where Interactive Technology was used in different parts of the course), Carnaghan and Webb (2005) found evidence of student satisfaction, with exam improvement only for items closely related to that displayed in class.

In the author's experience, the students seem to enjoy using the clickers and are competitive with each other in terms of who can click their answer quickest and get it right. To gauge the students' reaction, at the mid-point of the two semesters the author utilized this technology, the students were asked to anonymously write down what they liked about the class, what they didn't like, and suggested changes. A manila envelope was passed around in which the students enclosed their comments so it would be truly anonymous. Out of 98 responses over the two semesters, the top three themes regarding what was positive about the class were (1) using the Interactive Technology (noted by 61 students), (2) feeling that they paid more attention in class/liked the discussions due to the Interactive Technology (noted by 25 students), and (3) liking the class because they felt it was interesting (noted by 25 students). In terms of dislikes, there were only two negatives noted by at least two students each semester: the high price of the text book (noted by five students) and overuse of PowerPoint slides (noted by four students). The author knew the students liked using the Interactive Technology but was pleasantly surprised to see few negatives raised. Finally, in terms of the suggested changes, the only one that specifically related to the use of Interactive Technology was that two students each term wanted the participation grade to be worth more then five percent of the final grade.

The objectives of using Interactive Technology are to enhance communication and interaction so there is increased attention, interest, preparation, and retention of class materials by the students. To assess this, faculty can examine changes in course evaluations, attendance, test scores, and overall student performance in a course over a period of several semesters.

\section{CONCLUSION}

"Professors must embrace change and view it as a chance to augment, extend, and in some cases rejuvenate their teaching (Celsi and Wolfinbarger 2002, p. 64). Interactive Technology can be a positive change in the classroom that can enhance communication for both the professor and the students through increased interaction. "Besides encouraging participation and interaction with audience members, they also provide presenters with instantaneous, high-quality feedback, which can then be used to improve the informational value of almost any session. (Merritt 2000)."

In utilizing this technology it is recommended that a professor start slowly at first, such as using it just for participation with one course or selecting a course in which interaction and communication has been problematic, 
such as a course taught with a traditional lecture format. Then, the professor needs to work with their publishers to get the support needed for the training and materials based on the size of their class and the number of books being ordered. One problem with bundling materials with the textbook is that it eliminates or reduces the ability of the students buying used textbooks from non-University suppliers. Also, it is recommended that faculty practice early and often with the technology because even though it is not difficult to learn, they do want to be comfortable with it in front of the students. Finally, the professor needs to get the students' input often throughout the term on how they like the technology and utilize that input to improve their presentations and interaction with the students. By using this innovation to ask questions of the students, the professor gains buy-in from the students and the students appreciate having a say in the course. Thus, Interactive Technology can help professors enhance classroom communication so there is increased attention, interest, preparation, and retention of class materials by students. 


\section{REFERENCES}

1. Bradley, B. (2005), personal email communication and quote from Turning Technologies (January 27).

2. Carnaghan, C. and A. Webb (2005), Investigating the Effects of Group Response Systems on Learning Outcomes and Satisfaction in Accounting Education, working paper from the School of Accountancy at the University of Waterloo (cacarnag@uwaterloo.ca).

3. Celsi, R.L. and M. Wolfinbarger (2002), Discontinuous Classroom Innovation: Waves of Change for Marketing Education, Journal of Marketing Education 24 (1), p. 64.

4. $\quad$ eInstruction (2004), CPS: Ideas for Use, handout from 2004 Society of Marketing Advances Conference.

5. Hatch, S. (2003), ARS Systems: Creativity and Planning Required, Corporate Meetings \& Incentives 22 (11), 35 .

6. Karakaya, F., T.L. Ainscough, and J. Chopoorian (2001), The Effects of Class Size and Learning Style on Student Performance In A Multimedia-Based Marketing Course, Journal of Marketing Education 23 (2), 84.

7. Krantz, M. (2004), Audience Response Systems=Marketing Tool, Meeting News 28 (5), 5.

8. Kurdziel, J. (2005), Engaging Students in Large Lectures Using a Classroom Response System, www.crlt.umich.edu/faculty/JoKurdziel02-05.pdf (accessed June 27, 2005).

9. Liu, D. and L. Beamer (1997), Multimedia as a Teaching Tool in Business Communication Course Delivery, Business Communication Quarterly 60 (2), 51.

10. Massey, A.P., S.A. Brown, and J.D. Johnston (2005), It's All Fun and Games. Until Students Learn, Journal of Information Systems Education 16 (1), 9.

11. Merritt, M. (2000), WHAT ARE THEY THINKING? Presentations 14 (4), 86.

12. Pelletier, S. (2004), Grand Rounds Go Interactive, Medical Meetings 31 (2), 15.

13. Roberts, S. (1999), Harnessing the Future, Ivey Business Journal 64 (2), 10.

14. Serva, M.A. and M.A. Fuller (2004), Aligning What We Do and What We Measure in Business Schools: Incorporating Active Learning and Effective Media Use in the Assessment of Instruction, Journal of Management Education 28 (1), 19.

15. Stiefelhagen, R., X. Chen, and J. Yang (2005), Capturing Interactions in Meetings with Omnidirectional Cameras, International Journal of Distance Education Technologies 3 (3), 34.

16. Stone, L.L., G.M. Escoe, and R. Schenk (1999), Multimedia Instruction Methods/Comments, Journal of Economic Education 30 (3), 265.

17. Terreri, A. and T. Simons (2005), What Are They Thinking? Presentations 19 (2), 36.

18. Unmuth, K.L. (2004), Wichita, Kan., College Students Try Out Classroom Interaction Technology, Knight Ridder Tribune Business News Washington (March 30), 1. 